\title{
The Extent to Which Students at the University of Jordan Possess Life Skills Methods and Their Ability to Employ Them in Stressful Life Situations
}

\author{
Asre Ali Alramamna, Raed Ahmad Alkriemeen \\ Department of Educational Science, Al-Salt Faculty of Humanitarian Sciences, Al-Balqa Applied University, Jordan
}

Received October 17, 2020; Revised December 14, 2020; Accepted January 20, 2021

\section{Cite This Paper in the following Citation Styles}

(a): [1] Asre Ali Alramamna, Raed Ahmad Alkriemeen, "The Extent to Which Students at the University of Jordan Possess Life Skills Methods and Their Ability to Employ Them in Stressful Life Situations," Universal Journal of Educational Research, Vol. 9, No. 1, pp. 85 - 98, 2021. DOI: 10.13189/ujer.2021.090110.

(b): Asre Ali Alramamna, Raed Ahmad Alkriemeen (2021). The Extent to Which Students at the University of Jordan Possess Life Skills Methods and Their Ability to Employ Them in Stressful Life Situations. Universal Journal of Educational Research, 9(1), 95 - 98. DOI: 10.13189/ujer.2021.090110.

Copyright $\bigcirc 2021$ by authors, all rights reserved. Authors agree that this article remains permanently open access under the terms of the Creative Commons Attribution License 4.0 International License

\begin{abstract}
The study aimed to find out the extent to which students at the University of Jordan possess life skills and methods of employing them in stressful life situations. The study sample consisted of (1898) randomly chosen male and female students in the second semester of the academic year 2019/2020. The study adopted two scales to measure life skills and stressful life situations. The results showed that the level of stressful life situations was to a high extent, the most common of which are social situations. And students possess a moderate level of life skills, the most used of which are communication skills with others, and there are no differences in the level of life skills. It is attributed to the variable of gender, the academic year, and the existence of differences in the level of life skills attributed to the variable of the college in favor of human faculties. In addition, there was statistically significant differences in the degree of stressful life situations attributed to the variable of gender in favor of males, and to the variable of college in favor of human faculties, and the absence of statistically significant differences in the degree of stressful life situations referred to the academic level, and the presence of a positive correlation between the life skills, and their utilization in stressful life situations. The study recommends developing the skills of university students and upgrading them by encouraging students to develop their mental, social and emotional skills.
\end{abstract}

Keywords Life Skills, Stressful Life Situations, Jordan University Students

\section{Introduction}

The rapid development in digital and cognitive technological fields and the vast scientific changes in the economic, social, cultural and educational structures imposed major changes in the lifestyle on the ground in all societies, regardless of the boundaries of space and time, which highlighted the need to provide education capable of developing the life skills of the learner by diversifying stimuli in teaching and learning situations; To have an impact on increasing the learner's motivation and excitement to participate in and continue learning more. Education in the context of life skills has an impact on the behavior of the individual and gaining him/her the right positive attitudes in his/her practical life, and providing opportunities for growth in order to achieve his/her goals in the future in light of real life problems. Based on that, the educational systems have paid great attention to highlighting the standards of learning within the aspects of various life skills. Right up to the stage of basic, secondary and university education in different disciplines, devote these skills and make them a reality for the learner to 
practice in his/her daily life in a better way.

The changes witnessed in recent years in the scientific, technological, technical and cognitive fields led to radical changes that included all the purposes of life, which resulted in the emergence of an era of pressures and emotions that have become among the most dangerous phenomena that threaten the life of the contemporary individual, and there is no doubt that these pressures are faced by the university student whether in his/her family, within the university campus, or in the society in which he/she lives, these influences cannot be ignored, denied or overlooked in any way. If the individual is unable to cope with and adapt to them, those influences resulting from social, personal, family, material or developmental sources will become the beginning of many mental disorders, such as anxiety, stress and depression [1].

The issue of life skills has received great attention in international and regional forums. The Arab League Summit (2001) meeting in Jordan indicated in the Arab Childhood Framework document the need to enable the child to have his/her right to a quality upbringing, education and learning that raises his/her creativity and innovation capabilities, creates Moral and social values, and develops life skills [2].

The process of acquiring life skills is one of the important outcomes of the modern and contemporary curriculum at any stage of study, and this matter is not limited to a specific subject without the other subjects, as it is a joint responsibility from which no major can be exempt, and the reference is that education, in its essence, is concerned with the acquisition of life skills that qualify learners to live with people and interact with them and enable them to work and participate in the development process [3].

El-Arini [4] defined life skills as: the ability to perform a number of tasks related to an individual's life in his/her interaction with daily life with the aim of reaching the highest degree of utilization of his/her potential with the least effort, the fastest time, and the lowest possible cost. As for the Turk [5], he defined life skills as the skills that embody the reality of education in terms of its function and significance and give meaning to learning, as life skills link what the student learns and the psychological, emotional, social and intellectual pressures he faces through increasing his/her ability to control his/her behavior and adapt to the surrounding reality, in addition to increasing his/her self-confidence and self-esteem to meet the real-life challenges, reduce anxiety, and improve his/her psychological state.

Zadeh, Awang, Ismail and Saher [6] indicated that the student's acquisition of life skills achieves empowerment, the ability to increase his/her distinction in study and raise his/her academic achievement level, in addition to that it enables the student to think seriously about working with his/her utmost effort to learn and acquire skills with greater confidence without being affected by external pressures, and to adapt to the surrounding circumstances and overcome them when they occur, because life skills help $\mathrm{him} /$ her solve real-life problems, in addition to increasing his/her motivation towards learning and discovery.

Hodge, Danish \& Martin [7] believe that a student's life skills are related to his/her ability to face life situations. It provides him/her with the competencies and skills for adaptation, coexistence and success, in addition to providing him/her with the capabilities of communication and interaction with others, besides that life skills help to shape the personality of the individual, refine it and prepare $\mathrm{him} / \mathrm{her}$ to meet the challenges of the times and the problems of daily life to be a creative, productive, and active person locally and globally, capable of development and improvement, and the creating the change. Life skills can be described as skills that contribute to individuals' understanding of themselves and their awareness of their abilities through their practical performance that they practice to meet life's requirements and problems in order to reach the desired goals.

Zins et al [8] noted that life skills programs were present in school history early on, but they were not familiar at the time, and were called mystery programs, because they search in the deep, mysterious secrets of life and not its superficial secrets that were present in most school curricula, and they were facing natural resistance from some students and parents who feared that life skills programs would be a disguised religion, and with the passage of time they knew that they are performance skills that help the individual adapt to the society in which they live. In the beginning, these programs were directed to the presidents, and then they were presented to other levels of people until they developed into the programs currently in effect.

Euskaus et al [9] believed that life skills represent a set of performances that make the individual able to successfully manage the interaction between themselves and others and between him/her and the environment and society to face the problems they face in their lives. For example, the individual must have the ability to communicate and linguistic communication with others, and this matter helps him/her to present his/her thoughts, opinions and feelings and accept differences and viewpoints as these situations are features that require responses that are reflected by the type of behavior issued by the individual that helps him/her in building the future. In addition, Euskaus et al [9] indicated that enabling the individual to master the practice of life skills makes him/her feel confident and raises the level of confidence, admiration and pride of other people towards him/her.

Alkriemeen [10] also presented a set of life skills domains that can be summarized as follows: First: Emotional skills, including emotional control, emotional capacity, tolerance and flexibility, the ability to adapt and keep pace with change, and appreciation of the feelings of others. Second: social skills that include self-respect, 
responsibility, respect for opinion and viewpoints Third: Mental skills, which include the ability to properly plan, critical thinking, innovation and creativity, conduct experiments and perceive relationships, and the ability to self-learn and predict events.

The literature has referred to a multiplicity of life skills, including the skill of dialogue and discussion, the skill of problem solving, the skill of effective communication and the development of the mind habits represented in innovation, creativity, discovery and other social skills related to activities and building social relationships [1, $11]$.

The United Nations International Children's Emergency Fund (UNICEF) (2005) has classified life skills into the skill of communication, interpersonal relationships, cooperation and team work, the skill of managing life stress, the ability to collect information, the skill of empathy and emotion management, and mental skills such as creative and critical thinking [11].

Cognitive theory confirms that the basis for solving problems and the interactions between people and each other are relying on the cognitive side, because it contributes to reducing and preventing impulsive negative behaviors, so problem solving can be considered as an important part of life skills programs that help reduce stressful situations and control decision-making. In addition, life skills programs include interesting and enjoyable methods of teaching, including, but not limited to, observation, role play, acting and peer education [12].

Although life skills help the individual to adapt psychologically, emotionally, socially and mentally, Yadav and Iqbal [13] believe that skills differ from adaptation. Adaptation consists of the individual's reactions that are characterized by the mechanism. As for skills, they use defense mechanisms in psychological aspects such as controlling emotions, emotional expression and both emotional and social sensitivity, such as self-respect, taking responsibility, and forming relationships, which include conscious efforts in dealing with things and events that the individual could not adapt to [13].

Stressful life events are one of the main aspects that characterize our contemporary life, and these events are nothing but a reaction to the sharp and rapid changes that have occurred in all areas of life, which are the main cause of the injury of organic diseases, and the feeling of many psychological and social problems that afflict Individual [14].

Based on the above, psychological stress appears as a result of the interactions that occur within the individual according to external stimuli to which he/she is exposed, so that his/her response patterns occur, whether they are physical responses with all his/her preparations, physical, psychological or behavioral, which arise as a result of these stimuli [15], While Badran [16] explains that psychological pressures occur as a result of external pressures to which the human being is exposed and creates a state of difference in balance according to experience, which results from his/her awareness of the threats facing him/her, a group of symptoms that coincide with exposure to a stressful situation that leads to physiological, emotional and behavioral changes.

From this standpoint, many of the results of studies related to life skills, such as the study of Camirea, Kendellena, Rathwellb \& Turgeon [17], have shown that training students in life skills through thoughtful programs and planned experiences, helps them with psychological and social adjustment, and achieves self-esteem, self-confidence and positive adaptation to his/her surroundings, which raises his/her academic achievement and achievement capabilities.

Life skills represent a contemporary educational trend, and an increasing interest among educators and psychologists because of their crucial role in enabling the individual to face different life situations, as they are the basis for his/her ability to adapt to the reality of his/her cultural, social, ethnic and religious environment, and it is the guarantee for the individual's acquisition of the ability to solve Social problems and qualitative adaptation to reality [18].

This is consistent with many studies that have shown the relationship between possessing life skills such as communication, coexistence, adaptation, understanding and the ability to face life situations. The study of Roth, Assor, Maymon \& Kaplan [19] has shown that the development of student life skills has a positive effect on Self-development and adaptation to one's gender, the study of Rudy, Sheldon, Awong \& Tan [20] which demonstrated the impact of life skills on success, achievement and adaptation to the environment, and the Radwan study [21] aimed to reveal the effectiveness of a counseling program based on focusing on developing the life skills of Al-Azhar University students on a basic sample of (382) male and female students. The results of the study found that the total life skills level of the members of the experimental group before implementing the program reached (180.9) degrees with a relative weight $(65 \%)$ and with a medium degree. In addition, there were statistically significant differences among the members of the experimental sample on the scale of life skills and on the psychological state post-scale due to the application of the skills of focus sessions.

A study conducted by Sharif, Al-Dhalayn, Suleiman [22] aimed at knowing the effectiveness of a training program for some life skills and its impact on reducing psychological pressures among students of the lower basic stage in Karak Governorate, the Hashemite Kingdom of Jordan. The study adopted the semi-experimental approach. The study sample was (60) students who were randomly selected. The results of the study revealed that there are statistically significant differences between the average degrees of school psychological, emotional, and family pressures and the social level in favor of the experimental 
group in the post application. As for the study of Mekala, Aras \& Jayaseelan [23] in India, it aimed to identify the effect of positive life skills on reducing suicide intentions among university and college students. In a study conducted by Al-Nuaimi and Al-Khazraji [24], it indicated that students of Diyala University have a good level of life skills, and there is no statistically significant difference between males and females and specialization (human-scientific) in the level of life skills.

Jordanian universities strive to pay attention to their students because of the importance of this category in building and developing societies in the near future, and the interest is represented by the efforts made by societies towards them, or what the family and the university do in terms of prevention and care for these students, but this does not obviate the existence of obstacles in their lives, which prevent them from fully carrying out their role, including the stressful life situations that students may be exposed to, which may make them feel harassed and stressed, and that would have a negative impact on them in one or more aspects of their lives [25].

\subsection{Research Problem and Questions}

The researchers noted, through their academic and university experience, that there are a number of diverse life skills, whether emotional, social, mental or behavioral skills that students possess in a disparate manner among themselves according to the cultural, intellectual, geographical and social environments, which represent the student's personal and intellectual identity. It enables them to successfully interact to face daily life situations at the personal, family, environmental and community levels in a positive, more effective and perfect manner, as well as enable them to adjust psycho-socially and achieve a better future for them despite the stressful life conditions and situations that the Jordanian society lives, where students face in various stages of Education, especially the university stage, multiple pressures that affect their intellectual and life personality and their overall social adaptation in its different circles, and while facing some stressful situations - and through teaching communication with its different methods - they try to respond to them in a variety of ways. Some of them can deal with the event flexibly and deliberately, bear the pressure and adapt to it, and some of them deal with rigid and negative behavior, and perceive it as a dangerous threat, which increases the intensity of their feeling of psychological pressure, and this is based on the personal meanings, and the special connotations that these give to their methods of dealing with these events, which leads to the emergence of many negative effects, such as poor performance, a feeling of frustration and an inferior view of events and future life, and the physical, psychological, and behavioral disturbances they cause, all of which affect life skills according to the environmental influences and their magnitude in terms of how quickly they are affected by daily life pressures according to their psychological state and are positively related to their personal aspects, such as skills, abilities, etc., and in light of the above, the study problem is to answer the following questions:

1. What is the degree of stressful life situations among University of Jordan students?

2. What is the level of life skills of students at the University of Jordan?

3. Are there statistically significant differences at the level of significance $(\alpha=0.05)$ between the mean scores of students in life skills due to the variable of gender, academic year and college?

4. Are there statistically significant differences at the level of significance $(\alpha=0.05)$ between the mean scores of students in stressful life situations due to the variable of gender, academic year and college?

5. Is there a statistically significant relationship between each of the life skills and the stressful life situations of the University of Jordan students?

\subsection{Objectives of the Study}

The study aimed to find out the extent of students at the University of Jordan possessing life skills methods and their ability to employ them in stressful life situations, and their differences according to the academic year, type of college, and gender, and whether there is a relationship between them.

\subsection{Significance of the Study}

The current study gains its significance from the significance of the study variables and is represented in the following:

\subsubsection{Theoretical significance}

The study may contribute to providing information and enriching scientific knowledge about stressful life situations and life skills, which every university student is supposed to possess, and the importance of each of the study variables on the personality of the individual and its role in psychological and social adjustment and directing responses of individuals' behavior towards achieving the best practice of skills.

\subsubsection{Practical significance}

- $\quad$ Specialized people interested in the field of human development and training in youth centers and university program planners can benefit from its results for the purpose of employing and activating them in improving students' performance in particular and the performance of individuals in other institutions in general.

- It is hoped that the results of the study will contribute to enriching and generating more studies in other areas of different life skills. 
- $\quad$ Researchers and interested persons can also benefit from the study tools that the researchers developed.

\subsection{Conceptual and Procedural Definitions of the Study}

Life skills: defined by Al-Sayed [26] as: the individual's ability to adapt positively to his/her personal and social life problems, includes: the ability to manage time, negotiation and dialogue - communication and social communication good use of available resources and good behavior in emergency situations - interaction with others - The ability to make decisions - respect for the business organization.

Procedurally, it is defined as the respondent's score obtained on the life skills scale used in the current study, through the following three dimensions: (communication skills and communicating with others, problem-solving skills, finding solutions, evaluating alternatives and making appropriate decisions, and skills related to the academic aspect).

Stressful life situations: Shoukair [27] defines them as: a group of internal and external stressful sources that an individual is exposed to in his/her daily life, which results in a weakness in his/her ability to respond appropriately to the situation, as well as accompanying emotional and physiological disturbances that affect other aspects related to his/her personality.

It is defined procedurally as the respondent's score obtained on the stressful life situations scale used in the current study, through the following seven dimensions: (family, economic, academic, social, emotional, personal, and health stressful life situations).

\subsection{The Study Determinants}

The study determinants are represented by the following human, spatial and temporal limitations: Students of the University of Jordan in Amman, Jordan, for the first semester of the academic year 2019/2020, and the results of the study are determined and circulated on the seriousness of the study sample in responding to the study scales, and the psychometric characteristics they have related to reliability and consistency.

\section{The Study Methodology}

The current study adopted the descriptive correlational approach.

\subsection{Study Population and Sample}

The study population consisted of all the students of the University of Jordan, whose number is $(37,950)$ male and female students from various scientific and humanitarian colleges, based on the statistics of the admission and registration unit at the University of Jordan for the second semester of the academic year 2019/2020. A random sample of (1898) male and female students was chosen. The study sample represented $5 \%$ of the original study population (Table 1)

Table 1. Distribution of the study sample based on the study variables

\begin{tabular}{|c|c|c|c|c|}
\hline \multirow{2}{*}{ Demographic variable } & Categories & Distributed questionnaires & $\begin{array}{c}\text { Retrieved } \\
\text { questionnaires }\end{array}$ & Percentage \\
\hline \multirow{2}{*}{ Gender } & Male & 1101 & 1070 & $58 \%$ \\
\cline { 2 - 5 } & Female & 797 & 780 & $42 \%$ \\
\hline \multirow{3}{*}{ Academic year } & First year & 265 & 254 & $14 \%$ \\
\cline { 2 - 5 } & Second year & 418 & 409 & $22 \%$ \\
\cline { 2 - 5 } & Third year & 645 & 633 & $34 \%$ \\
\cline { 2 - 5 } & Fourth year & 569 & 554 & $30 \%$ \\
\cline { 2 - 5 } College & Humanity & 1051 & 823 & $55 \%$ \\
\hline \multirow{2}{*}{} & Scientific & 847 & 1850 & $45 \%$ \\
\hline
\end{tabular}




\subsection{Research Instruments}

The Study scales were developed as following:

\subsubsection{First: life skills}

After reviewing a number of sources of educational literature, studies and previous research in the field of life skills, the life skills scale developed by Wafi [28] was modified and consisted of (33) statements distributed into three domains that dealt with the most important life skills of the university student, namely: Communication skills with Others (11 items), decision-making and problem-solving skills (11 items), and academic (study) skills (11 items).

Validity: The validity of the scale was verified by presenting the scale to (5) of the jury members specialized in the field of educational psychology at Al-Balqa Applied University and the University of Jordan, and taking their opinions on the appropriateness of the scale's domains and its statements, the soundness of its phrasing, and the extent of matching the statement in terms of its representation and its relevance to the domain and to the category to which the study sample belongs, as well as in terms of the suitability of its linguistic formulation, and based on the comments of the jury members, the wording of (8) statements had been amended linguistically.

Reliability: The scale reliability was verified by extracting the significance of internal consistency coefficient of the scale through the test-retest method by administering the scale, and re-administering it after two weeks on (40) male and female students from outside the study sample, as the reliability value was $(0.84)$, It was considered an appropriate value for the purposes of the study (Table 2).

Table 2. Cronbach's Alpha and test-retest internal consistency coefficients of the life skills scale

\begin{tabular}{|c|c|c|}
\hline Domain & $\begin{array}{c}\text { Test-retest } \\
\text { reliability }\end{array}$ & $\begin{array}{c}\text { Internal } \\
\text { consistency }\end{array}$ \\
\hline $\begin{array}{c}\text { Skills of communication with } \\
\text { others }\end{array}$ & 0.86 & 0.81 \\
\hline $\begin{array}{c}\text { Skills of decision making and } \\
\text { problem solving }\end{array}$ & 0.83 & 0.78 \\
\hline Academic skills & 0.85 & 0.80 \\
\hline Total life skills & 0.84 & 0.81 \\
\hline
\end{tabular}

It is noted from Table (2) that the values of the test-retest reliability coefficients ranged between (0.83-0.86) and the total (0.84), and the internal consistency values were between $(0.78-0.81)$ and the total $(0.81)$, which are suitable values for the study purposes.

The correlation coefficients of the items of the scale with the total score and with the domains to which they belong were extracted by administering it to a pilot sample that consisted of (40) male and female students from the University of Jordan. The correlation coefficients of the statements with the whole scale ranged between (0.35-0.760), and with the domain $(0.353-0.911)$ (Table 3).

It is evident from Table (2) that the items correlation coefficients with the domain and the whole scale were statistically significant at the levels of significance $\alpha=$ $(0.05)$ and $(0.01)$, so none of them was deleted, and no items was also deleted based on the criterion adopted by the researchers, which the correlation coefficients should not be less than $(0.30)$.

Table 3. The correlation coefficients between items, the overall scale and the domain to which they belong on the life skills scale

\begin{tabular}{|c|c|c|c|c|c|c|c|c|}
\hline Item \# & $\begin{array}{l}\text { Correlation to } \\
\text { the scale }\end{array}$ & $\begin{array}{c}\text { Correlation } \\
\text { to the } \\
\text { domain }\end{array}$ & Item \# & $\begin{array}{l}\text { Correlation to } \\
\text { the scale }\end{array}$ & $\begin{array}{c}\text { Correlation } \\
\text { to the } \\
\text { domain }\end{array}$ & Item \# & $\begin{array}{l}\text { Correlation to } \\
\text { the scale }\end{array}$ & $\begin{array}{c}\text { Correlation to the } \\
\text { domain }\end{array}$ \\
\hline 1 & $.566^{* *}$ & $.529^{* *}$ & 15 & $.525^{* *}$ & $.549 * *$ & 29 & $0.346^{*}$ & $.911^{* *}$ \\
\hline 2 & $.542^{* *}$ & $.444^{*}$ & 16 & $.372 *$ & $651 * *$ & 30 & $0.760 * *$ & $.413^{*}$ \\
\hline 3 & $.382^{*}$ & $828 * *$ & 17 & $.418^{*}$ & $.421 *$ & 31 & $0.641 * *$ & $.721 * *$ \\
\hline 4 & $.510^{* *}$ & $.395 *$ & 18 & $.620 * *$ & $812^{* *}$ & 32 & $0.611 * *$ & $.811^{* *}$ \\
\hline 5 & $.442^{*}$ & $.581 * *$ & 19 & $.526 * *$ & $.603 * *$ & 33 & $0.734 *$ & $.780 * *$ \\
\hline 6 & $.703^{* *}$ & $.353^{*}$ & 20 & $.410^{*}$ & $.440^{*}$ & & & \\
\hline 7 & $.444^{* *}$ & $.669^{* *}$ & 21 & $.380^{*}$ & $.610^{* *}$ & & & \\
\hline 8 & $.420^{*}$ & $.513^{* *}$ & 22 & $.533 * *$ & $.433 *^{*}$ & & & \\
\hline 9 & $.530 * *$ & $.612^{* *}$ & 23 & $.521 * *$ & $.498 * *$ & & & \\
\hline 10 & $.513^{* *}$ & $.530 * *$ & 24 & $630 * *$ & $.540 * *$ & & & \\
\hline 11 & $.430 * *$ & $.395 *$ & 25 & $.421 *$ & $700 * *$ & & & \\
\hline 12 & $.480 * *$ & $.393 *$ & 26 & $.603 * *$ & $.477 *$ & & & \\
\hline 13 & $.401 *$ & $.705^{* *}$ & 27 & $.454 * *$ & $521 * *$ & & & \\
\hline 14 & $.492^{* *}$ & $.594 * *$ & 28 & $.526 * *$ & $.481 *$ & & & \\
\hline
\end{tabular}

* statistically significant at significance level $(0.05) * *$ Statistically significant at significance level $(0.01)$ 


\subsubsection{Scale scoring}

The scale consisted in its final form of (33) items, and it is of the type of self-filled. The student answers according to the five-point Likert scale (strongly agree: 5 , agree: 4 , neutral: 3 , disagree: 2 , strongly disagree: 1 ) The following equation was used to extract the range for each of the three levels: (the upper class - the lower class) / 3, i.e. (5-1) divided by (3) equal to (1.33), and therefore (1- 2.33) represents the low level, and (2.34-3.67) corresponds to the moderate level, and (3.68 - 5) corresponds to the high level.

\subsubsection{Second: Stressful life situations}

After reviewing the educational literature and related previous studies, and consulting some specialists, the life skills scale developed by Al-Banna [25] was adopted and developed with (54) items distributed in seven domains, namely: stressful family life situations (8) items, and stressful economic life situations (8) items, stressful academic life situations (7) items, stressful social life situations (7) items, stressful emotional and personal life situations (7) items, and stressful health life situations (7) items.

Validity of the content: The tool was presented to (8) university professors who specialize in educational psychology, curricula and teaching methods, taking their opinions about the integrity and clarity of the statements in terms of linguistic and scientific terms, and the belonging of each statement of the scale to the domain that it measures and the extent of its consistency with the category to which the sample of the study belongs to. Based on the comments of the jury members, the wording of (6) statements have been modified linguistically, and one from the scientific side.

Reliability of the scale: The test-retest method was used to ensure the reliability of the scale by administering the scale, and re-administering it after two weeks to a group of students that was excluded from the original study sample, consisting of (40) male and female students (Table 4).

It is evident from Table (4) that the consistency coefficients ranged between $(0.76-0.81)$ and the total reached $(0.80)$, and the internal consistency coefficients ranged between (0.74-0.84), and the total reached (0.77), which are suitable values for the purposes of scientific research.
Table 4. Cronbach's Alpha and test-retest internal consistency coefficients of the life skills

\begin{tabular}{|c|c|c|c|}
\hline Item \# & Domain & $\begin{array}{c}\text { Test-retest } \\
\text { reliability }\end{array}$ & $\begin{array}{c}\text { Internal } \\
\text { consistency }\end{array}$ \\
\hline 1 & $\begin{array}{c}\text { Family stressful life } \\
\text { situations }\end{array}$ & 0.81 & 0.74 \\
\hline 2 & $\begin{array}{c}\text { Economic stressful } \\
\text { life situations }\end{array}$ & 0.77 & 0.78 \\
\hline 3 & $\begin{array}{c}\text { Academic stressful } \\
\text { life situations }\end{array}$ & 0.79 & 0.74 \\
\hline 4 & $\begin{array}{c}\text { Social stressful life } \\
\text { situations }\end{array}$ & 0.81 & 0.76 \\
\hline 5 & $\begin{array}{c}\text { Emotional stressful } \\
\text { life situations }\end{array}$ & 0.80 & 0.77 \\
\hline 6 & $\begin{array}{c}\text { Personal stressful } \\
\text { life situations }\end{array}$ & 0.80 & 0.77 \\
\hline 7 & $\begin{array}{c}\text { Health stressful life } \\
\text { situations }\end{array}$ & 0.76 & 0.84 \\
\hline \multicolumn{2}{|c|}{ Total stressful life situations }
\end{tabular}

In order to extract the internal consistency psychometric properties of the scale, the correlation coefficients of the scale items with the total score and with the domain to which they belong were extracted using a pilot sample consisting of (40) male and female students. The correlation coefficient of the items with the whole scale ranged between (0.368-0.822), and with the domain (0.380-0.901) (Table 5).

It is evident from Table (5) that the items correlation coefficients with the domain and the overall scale were statistically significant at the significance levels $\alpha=(0.05)$ and $(0.01)$, so none of them were omitted, indicating that the domains of the scale are suitable for measuring stressful life situations.

\subsubsection{Scale scoring}

The tool consisted in its final form of (54) items, and it is of the type of self-report that students answer in light of the five-point Likert scale, according to the following scores: (Strongly agree: 5 , agree: 4 , neutral: 3 , disagree: 2 degrees, Strongly disagree: 1), and to calculate the level of stressful life situations and the most common ones, and to judge the level of arithmetic averages for the items, the statistical criterion was adopted using the following equation: (the upper class - the lower class) / 3 , i.e. (5-1) divided by (3) It is equal to (1.33), and therefore: from (1-2.33) a low level, (2.34-3.67) a medium level, and (3.68-5) corresponds to a high level. 
Table 5. the correlation coefficients between items, the overall scale and the domain to which they belong on the life skills scale

\begin{tabular}{|c|c|c|c|c|c|c|c|c|}
\hline Item \# & $\begin{array}{l}\text { Correlation to } \\
\text { the scale }\end{array}$ & $\begin{array}{l}\text { Correlation to } \\
\text { the domain }\end{array}$ & Item \# & $\begin{array}{l}\text { Correlation to } \\
\text { the scale }\end{array}$ & $\begin{array}{l}\text { Correlation to } \\
\text { the domain }\end{array}$ & Item \# & $\begin{array}{l}\text { Correlation } \\
\text { to the scale }\end{array}$ & $\begin{array}{c}\text { Correlation to } \\
\text { the domain }\end{array}$ \\
\hline 1 & $.566^{* *}$ & $.620 * *$ & 23 & $.456^{*}$ & $.809^{* *}$ & 44 & $.530 * *$ & $.901 * *$ \\
\hline 2 & $.542^{* *}$ & $.526 * *$ & 24 & $419^{*}$ & $.381 *$ & 45 & $.395^{*}$ & $.413^{*}$ \\
\hline 3 & $.382^{*}$ & $.410^{*}$ & 25 & $.423^{*}$ & $.459^{*}$ & 46 & $.393^{*}$ & $.521^{* *}$ \\
\hline 4 & $.510^{* *}$ & $.380^{*}$ & 26 & $412 *$ & $.591^{* *}$ & 47 & $.705^{* *}$ & $630 * *$ \\
\hline 5 & $.442^{*}$ & $.533^{* *}$ & 27 & $.723 * *$ & $.505^{* *}$ & 48 & $.594 * *$ & $.421 *$ \\
\hline 6 & $.703^{* *}$ & $.521 * *$ & 28 & $.811^{* *}$ & $0.584^{* *}$ & 49 & $.530 * *$ & $.603^{* *}$ \\
\hline 7 & $.502 * *$ & $.630^{* *}$ & 29 & $.375^{*}$ & $0.447 * *$ & 50 & $.395^{*}$ & $.454 * *$ \\
\hline 8 & $.420^{*}$ & $.421 *$ & 30 & $.439 * *$ & $0.424 *$ & 51 & $.393^{*}$ & $.581 * *$ \\
\hline 9 & $.368^{*}$ & $.612 * *$ & 31 & $.521 * *$ & $.809 * *$ & 52 & $.597 * *$ & $.491 *$ \\
\hline 10 & $.384 *$ & $.530 * *$ & 32 & $.630 * *$ & $.540 * *$ & 53 & $.603 * *$ & $.452 *$ \\
\hline 11 & $.430 * *$ & $.395^{*}$ & 33 & $.421^{*}$ & $.700 * *$ & 54 & $.532 * *$ & $.610^{* *}$ \\
\hline 12 & $.480 * *$ & $.393 *$ & 34 & $.603 * *$ & $.477^{*}$ & & & \\
\hline 13 & $.382 *$ & $.410^{*}$ & 35 & $.423^{*}$ & $.459 *$ & & & \\
\hline 14 & $.510 * *$ & $.380^{*}$ & 36 & $412 *$ & $.591 * *$ & & & \\
\hline 15 & $.442 *$ & $.533 * *$ & 37 & $.723 * *$ & $.505^{* *}$ & & & \\
\hline 16 & $.593 * *$ & $.502 * *$ & 38 & $.591 * *$ & $.620 * *$ & & & \\
\hline 17 & $.419 *$ & $.420 *$ & 39 & $.505 * *$ & $.526^{* *}$ & & & \\
\hline 18 & $.524 * *$ & $.386^{*}$ & 40 & $.584 * *$ & $.410^{*}$ & & & \\
\hline 19 & $.513 * *$ & $.384 *$ & 41 & $.447 * *$ & $.380 *$ & & & \\
\hline 20 & $.530 * *$ & $.419^{*}$ & 42 & $.424 *$ & $.533 * *$ & & & \\
\hline 21 & $.723 * *$ & $.423 *$ & 43 & $.591 * *$ & $.521^{* *}$ & & & \\
\hline 22 & $.822 * *$ & $.412 *$ & & & & & & \\
\hline
\end{tabular}

* statistically significant at significance level $(0.05) * *$ Statistically significant at significance level $(0.01)$

\section{Data collection procedure}

The researcher prepared the final version of the data collection tool, added the consent form and distributed the questionnaire package to the study subjects. The participants were informed about the aim, significance and expected outcome of the study and its impact in scientific field. In addition, the participants were informed to ask for help from one of the researchers in case they encounter any difficulties when filling in the questionnaire.

After that, the researcher asked the participants to return the questionnaire once it was filled in. and complete and valid questionnaires were used in the analysis process.

\section{Data processing}

Gathered data were processed and analyzed using the Statistical Package of Social Sciences (SPSS) (v.26, IBM Corporation). Descriptive statistics such as frequency, percentage, means and standard deviation, in addition to Pearson correlation factor, Cronbach's Alpha coefficient and one sample t-test were performed to get the study results.

\section{Results and Discussion}

\section{The results and Discussion of the first question:}

What is the degree of stressful life situations among students at the University of Jordan, and what is the order of their prevalence?

In order to answer this question, the means and standard deviations were extracted for the study sample on the domains of stressful life situations, and Table (6) illustrates this: 
Table 6. Means, standard deviations, ranks, and t-value for the domains of stressful life situations

\begin{tabular}{|c|c|c|c|c|c|c|}
\hline Item \# & Domain & $\begin{array}{l}\text { Standard } \\
\text { deviation }\end{array}$ & Mean & Degree & Rank & t value \\
\hline 1 & Family stressful life situations & .77 & 3.71 & High & 6 & 79.938 \\
\hline 2 & Economic stressful life situations & .86 & 3.77 & High & 5 & 43.847 \\
\hline 3 & Academic stressful life situations & .69 & 3.70 & High & 7 & 40.712 \\
\hline 4 & Social stressful life situations & .48 & 4.19 & High & 1 & 40.657 \\
\hline 5 & Emotional stressful life situations & .88 & 3.80 & High & 4 & 51.933 \\
\hline 6 & Personal stressful life situations & .54 & 3.98 & High & 2 & 85.545 \\
\hline 7 & Health stressful life situations & .53 & 3.82 & High & 3 & 42.140 \\
\hline \multicolumn{2}{|c|}{ Total stressful life situations } & .67 & 3.68 & High & & 72.280 \\
\hline
\end{tabular}

It is evident from table (6) that all the stressful life situations got a large degree, where the overall mean was (3.68), and with a standard deviation (.67). Stressful academic life is at the lowest mean of (3.70). This result appears to be justified, for when the student moves to the university, he/she interacts with a new environment, and students from different social and economic environments may be subjected to great pressure due to the lack of harmony between him/her and many of his/her colleagues who are in contact with them, in one way or another, whether in the economic level or the social environment, and even communication. Sometimes, This is reflected in the students' reluctance to participate in the exchange of views or even to participate in the activities of the university's extracurricular programs, in addition to the variation in the cultural pattern reflected on the dress as well, which represents the personal aspect, especially since the student at the university level has gone a long way in terms of maturity and morphology, and in this context, Wintre \& Bowers [29] indicated that $57.9 \%$ of university students, especially freshmen, are exposed to social situations and pressures when they move to the university due to the disparity in social environments and different cultures that each has methods of verbal communication and different interaction methods.

This result is consistent with the findings of Taylor's study [30], which showed that the most important life pressures faced by the student are weak coping skills and social communication among students, and this result is also consistent with the study of Ramsey and Sandler [31] which showed that the most important sources of psychological stress for the student are the social sources that are represented by (discomfort) through the student's inability to accept others, the his/her inability to form relationships with friends, the difficulty to learn and verbal communication, the low academic achievement rate, and the failure to invest free time constructively. As for social academic problems, it includes some of the problems that are involved in the source of the annoyance, as for the bad relationships, it is the difficulty of dealing with the teacher and the fixed system (routine) inside the educational campus or the classroom, in addition to the feeling of psychological loneliness.

\section{Results and discussion of the second question:}

What is the level of life skills of students at the University of Jordan?

To answer this question, the means and standard deviations were extracted for the study sample on the domains of life skills scale (Table 7).

It is obvious from table (7) that all life skills domains got a moderate level, where the overall mean reached (3.09) and a standard deviation (.69). Academic skills (teaching) were with a mean (3.11), the skills of decision-making and problem-solving obtained the lowest mean score of (3.07), and this result may be referred to the age and academic stage in which the university student experiences, as it is a stage that enables him/her to express him/herself verbally or Non-verbally, in a manner appropriate to his/her culture and position, as well as the ability to express the individual's desire in relation to a specific type of action that can facilitate his/her action. It also means the ability to ask about advice at a time of need, whether from colleagues or teachers, and this is often the goal of university education, which is based on the development of the integrated personality of the student in its various cognitive, emotional, social, spiritual and physical dimensions. Education in the university is a balanced preparation for productive life, and thus a different spread form of communication and interaction with the university student. This result was confirmed by Al-Sayed [26] who indicated that life skills give the learner direct experience, and this experience results through direct contact with people, objects and phenomena and interacting with them directly, making him/her able to face different life situations and the ability to overcome life problems and deal with them wisely. In addition, the findings of the present study are in line with the findings reported by Mekala, Aras \& Jayaseelan [23], which showed improvement in communication and coexistence skills among the students of the study, and the findings reported by Al-Khazraji and Al-Nuaimi [24] who reported that university students have a good level of life skills. 
The Extent to Which Students at the University of Jordan Possess Life Skills Methods and Their Ability to Employ Them in Stressful Life Situations

Table 7. Means, standard deviations, and ranks of the life skills domains

\begin{tabular}{|c|c|c|c|c|c|c|}
\hline$\#$ & Domain & $\begin{array}{c}\text { Standard } \\
\text { deviation }\end{array}$ & Mean & Degree & Rank & $\mathrm{t}$ value \\
\hline 1 & Skills of communication with others & .66 & 3.15 & Moderate & 1 & 48.282 \\
\hline 2 & Skills of decision making and problem solving & .71 & 3.07 & Moderate & 3 & 43.847 \\
\hline 3 & Academic skills & .70 & 3.11 & Moderate & 2 & 40.712 \\
\hline \multicolumn{2}{r|}{ Total life skills } & .69 & 3.09 & & & 79.938 \\
\hline
\end{tabular}

Table 8. Means and standard deviations of the gender, academic year, and college variables

\begin{tabular}{|c|c|c|c|c|c|}
\hline \multicolumn{2}{|c|}{ Variable } & Mean & $\mathrm{n}$ & Rank & Standard deviation \\
\hline \multirow{3}{*}{ Gender } & Male & 3.31 & 1070 & 1 & .77 \\
\cline { 2 - 6 } & Female & 3.06 & 780 & 2 & .63 \\
\hline \multirow{3}{*}{ Academic year } & First & 2.95 & 254 & 4 & .49 \\
\cline { 2 - 6 } & Second & 3.06 & 409 & 3 & .60 \\
\cline { 2 - 6 } & Third & 3.16 & 633 & 1 & .70 \\
\hline \multirow{2}{*}{ College } & Fourth & 3.10 & 1023 & 1 & .67 \\
\cline { 2 - 6 } & Humanity & 3.23 & 827 & 2 & .73 \\
\hline
\end{tabular}

\section{Results and discussion of the third question}

Are there statistically significant differences in the level of life skills attributable to gender, academic year and college?

To answer this question, the means and standard deviations of the study sample were calculated according to the variables of gender, academic year and college (Table 8).

It is evident from table (8) that male students obtained the highest mean scores for the gender variable and reached (3.31), and that students of the third year level obtained the highest mean scores for the variable of the academic year and reached (3.16). it is also obvious that the students from the humanitarian colleges obtained the highest mean score of (3.23) for the variable of the college, and to verify the statistical significance of the differences between the mean scores in the level of life skills of the study sample according to the variables of gender, the following test was conducted:

First: Independent Samples t-test to show the differences referred to gender variable (Table 9).

Table 9. Independent samples t-test for gender variable

\begin{tabular}{|c|c|c|c|}
\hline Life skills & F & t value & Sig \\
\hline Gender & 3.845 & 0.581 & 0.053 \\
\hline
\end{tabular}

**statistically significant at $(\alpha=0.05)$

It is evident from Table (9) that there are no statistically significant differences attributed to the gender variable.

Second: The ANOVA test to show the differences with the variable of the academic year, and Table (10) shows that:
Table 10. ANOVA test to measure the differences referred to the academic year variable

\begin{tabular}{|c|c|c|c|c|c|c|}
\hline \multicolumn{2}{|c|}{ Life skills } & $\begin{array}{c}\text { Sum of } \\
\text { squares }\end{array}$ & df & $\begin{array}{c}\text { Mean } \\
\text { squares }\end{array}$ & F & Sig \\
\hline \multirow{4}{*}{$\begin{array}{c}\text { Academic } \\
\text { year }\end{array}$} & $\begin{array}{c}\text { Between } \\
\text { groups }\end{array}$ & .198 & 4 & .066 & .313 & .816 \\
\cline { 2 - 7 } & $\begin{array}{c}\text { Within } \\
\text { groups }\end{array}$ & 19.430 & 1846 & .211 & & \\
\cline { 2 - 8 } & Total & 19.628 & 1850 & & & \\
\hline
\end{tabular}

**statistically significant at $(\alpha=0.05)$

It is clear from Table (10) that there are no statistically significant differences in the level of life skills due to the variable of the academic year.

Third: Independent Samples t-test to show the differences referred to the variable of the college, and Table (11) explains that:

Table 11. Independent samples t-test for college variable

\begin{tabular}{|c|c|c|c|}
\hline Life skills & F & t & Sig \\
\hline College & 3.565 & 0.561 & 0.043 \\
\hline
\end{tabular}

**statistically significant at $(\alpha=0.05)$

Table (11) shows that there are statistically significant differences due to the variable of the college and in favor of the human faculties.

This result appears to be justified, as male students have multiple experiences due to the prevailing gender pattern in society that enhances the mixing of males and their interaction within the community, and thus they are more able to communicate and solve problems than females, and students in human faculties, according to the nature of their studies, are more able to express themselves and communicate and interacting with others due to the nature of the theoretical subjects they study, and whenever the student moves from one academic year to another higher 
academic year, his/her familiarity with the university and the environment in which he/she studies makes him/her more experienced and acquires various social skills. Thus one finds that third-year students possess more social skills than First and second year students. This result is consistent with the result of Saad al-Din's study [32], which showed statistical differences in the level of tenth grade students' acquisition of life skills concepts in favor of males, and this result differs from the study of Al-Khazraji and Al-Nuaimi [24] which concluded that there was no statistically significant difference between males and females and specialization. (Humanitarian - scientific) in the level of life skills, and this may be due to the different nature of the two samples.

\section{Results and discussion of the fourth question:}

Are there differences at the level of significance (0.05) in the level of stressful life situations due to gender, academic year and college?

To answer this question, the means and standard deviations of the study sample were calculated according to the variables of gender, academic year and college (Table 12).

Table 12. Means and standard deviations for the gender, academic year and college variables

\begin{tabular}{|c|c|c|c|c|c|}
\hline \multicolumn{2}{|c|}{ Variable } & Mean & $\mathrm{n}$ & Rank & $\begin{array}{c}\text { Standard } \\
\text { deviation }\end{array}$ \\
\hline \multirow{2}{*}{ Gender } & Male & 3.86 & 1070 & 1 & .77 \\
\cline { 2 - 6 } & Female & 3.68 & 780 & 2 & .68 \\
\hline \multirow{3}{*}{$\begin{array}{c}\text { Academic } \\
\text { year }\end{array}$} & First & 3.51 & 254 & 4 & .80 \\
\cline { 2 - 6 } & Second & 3.63 & 409 & 3 & .82 \\
\cline { 2 - 6 } & Third & 3.86 & 633 & 1 & .97 \\
\hline \multirow{3}{*}{\begin{tabular}{c} 
College \\
\cline { 1 - 6 }
\end{tabular}} & Fourth & 3.80 & 554 & 2 & .88 \\
\cline { 2 - 6 } & Humanity & 3.78 & 1023 & 1 & .75 \\
\cline { 2 - 6 } & Scientific & 3.54 & 827 & 2 & .61 \\
\hline
\end{tabular}

It is evident from table (12) that the male category got the highest mean score for the gender variable and reached (3.86), and the students of the third year level got the highest mean score for the academic year variable and reached (3.86), while the students from the humanitarian colleges got the highest mean score, which was (3.78) for the college variable. To verify the statistical significance of the differences between the mean scores in the degree of stressful life situations in the study sample according to the gender variable, the following tests were conducted:

First: Independent Samples Test to show the differences referred to the gender variable (Table 13).

Table 13. Independent samples t-test to measure differences referred to gender variable

\begin{tabular}{|c|c|c|c|}
\hline Stressful life situations & $\mathrm{F}$ & $\mathrm{t}$ & $\mathrm{Sig}$ \\
\hline Gender & 2.654 & 0.431 & 0.051 \\
\hline
\end{tabular}

**statistically significant at $(\alpha=0.05)$
It is clear from Table (13) that there are no statistically significant differences attributed to the variable of gender.

Second: The ANOVA test to show the differences with the variable of the academic year, and Table (14) explains that:

Table 14. ANOVA test to measure the differences referred to the academic year variable

\begin{tabular}{|c|c|c|c|c|c|c|}
\hline \multicolumn{2}{|c|}{$\begin{array}{c}\text { Stressful life } \\
\text { situations }\end{array}$} & $\begin{array}{c}\text { Sum of } \\
\text { squares }\end{array}$ & df & $\begin{array}{c}\text { Mean } \\
\text { squares }\end{array}$ & F & Sig \\
\hline \multirow{4}{*}{$\begin{array}{c}\text { Academic } \\
\text { year }\end{array}$} & $\begin{array}{c}\text { Between } \\
\text { groups }\end{array}$ & 1.543 & 4 & .514 & .384 & .765 \\
\cline { 2 - 7 } & $\begin{array}{c}\text { Within } \\
\text { groups }\end{array}$ & 123.197 & 1846 & 1.339 & & \\
\cline { 2 - 8 } & Total & 124.740 & 1850 & & & \\
\hline
\end{tabular}

**statistically significant at $(\alpha=0.05)$

It is clear from Table (14) that there are no statistically significant differences in the degree of stressful life situations due to the variable of the academic year.

Third: Independent Samples t-Test to show the differences referred to the college variable (Table 15).

Table 15. Independent samples t-test to measure differences referred to college variable

\begin{tabular}{|c|c|c|c|}
\hline Stressful life situations & $\mathrm{F}$ & $\mathrm{t}$ & Sig \\
\hline College & 3.432 & 0.521 & 0.0139 \\
\hline
\end{tabular}

**statistically significant at $(\alpha=0.05)$

It is clear from Table (15) that there are statistically significant differences due to the variable of the college, and in favor of the humanitarian faculties.

This result appears to be justified. Female students are more vulnerable to stressful life situations due to the nature of society that imposes on the girl many restrictions that limit her ability to communicate with others, and the shyness of girls prevents them from carrying out social or interactive activities with colleagues within the university, and thus their capacity of communication and problem solving decreases, and in this context, Hamdi [33] believes that female students are exposed to more stressful life situations than males due to their weak social compatibility, which makes the ability to establish a positive social relationship in advance with colleagues, and prevents the student from actively participating in the management of seminars and parties and all university activities, and this applies to all female students in different academic stages and in different colleges, because of the similar characteristics and personal characteristics of female students at this stage and because of the similar nature of social pressures that the student faces at the university.

The researchers believe that the students' exposure to more stressful life situations can be due to the students' inability to satisfy their psychological needs, their self-acceptance, their enjoyment of a university life free from tensions, conflicts and anxiety, their enjoyment of close social relations, their participation in social and cultural activities and mixing with them, in addition to their acceptance of the customs, traditions and values of society 
that they live in it, and all this causes the student to maladjustment due to the social isolation imposed on her. This result is consistent with the result of the study of Al-Banna [25], which showed that there are no statistically significant differences in the domains of stressful life situations due to the gender variable (males - females) except for the domain of Stressful health life situations, and the differences were in favor of females, while this result was contrary to Taylor's study [30], which indicated that there are differences in the level of psychological stress other than the pressures of the university environment - due to the gender variable in favor of males. This difference might be referred to the differences between the samples' characteristics and differences in adopted data collection scales.

\section{Results and discussion of the fifth question}

Is there a relationship between both life skills and stressful life situations among University of Jordan students?

The extent of the correlation between each domain of life skills was tested with the domains of stressful life situations using the Pearson's correlation (Table 16).

Table 16. Pearson's correlation factor between the domains of life skills and the domains of stressful life situations

\begin{tabular}{|c|c|c|c|c|c|}
\hline \multirow{2}{*}{\multicolumn{2}{|c|}{ Domains of stressful life situations }} & \multicolumn{3}{|c|}{ Domains of life skills } & \multirow{3}{*}{$\begin{array}{c}\begin{array}{c}\text { Total life } \\
\text { skills }\end{array} \\
.224\end{array}$} \\
\hline & & \multirow{2}{*}{$\begin{array}{c}\text { Skills of } \\
\text { communication with } \\
\text { others } \\
002\end{array}$} & \multirow{2}{*}{$\begin{array}{c}\begin{array}{c}\text { Skills of decision } \\
\text { making and problem } \\
\text { solving }\end{array} \\
.274\end{array}$} & \multirow{2}{*}{$\begin{array}{c}\begin{array}{c}\text { Academic } \\
\text { skills }\end{array} \\
.290\end{array}$} & \\
\hline \multirow{3}{*}{ Family } & $\begin{array}{c}\text { Pearson's correlation } \\
\text { coefficient }\end{array}$ & & & & \\
\hline & Sig & .985 & .007 & .004 & .029 \\
\hline & $\mathrm{n}$ & 1850 & 1850 & 1850 & 1850 \\
\hline \multirow{3}{*}{ Economic } & $\begin{array}{c}\text { Pearson's correlation } \\
\text { coefficient }\end{array}$ & .274 & .113 & .303 & .156 \\
\hline & Sig & .007 & .274 & .003 & .130 \\
\hline & $\mathrm{n}$ & 1850 & 1850 & 1850 & 1850 \\
\hline \multirow{3}{*}{ Academic } & $\begin{array}{c}\text { Pearson's correlation } \\
\text { coefficient }\end{array}$ & .290 & .303 & .779 & .504 \\
\hline & Sig & .004 & .003 & .000 & .000 \\
\hline & $\mathrm{n}$ & 1850 & 1850 & 1850 & 1850 \\
\hline \multirow{3}{*}{ Social } & $\begin{array}{c}\text { Pearson's correlation } \\
\text { coefficient }\end{array}$ & .224 & .156 & .504 & .137 \\
\hline & Sig & .029 & .130 & .000 & .186 \\
\hline & $\mathrm{n}$ & 1850 & 1850 & 1850 & 1850 \\
\hline \multirow{3}{*}{ Emotional } & $\begin{array}{c}\text { Pearson's correlation } \\
\text { coefficient }\end{array}$ & .400 & .603 & .621 & .598 \\
\hline & Sig & .000 & .000 & .000 & .000 \\
\hline & $\mathrm{n}$ & 1850 & 1850 & 1850 & 1850 \\
\hline \multirow{3}{*}{ Personal } & $\begin{array}{c}\text { Pearson's correlation } \\
\text { coefficient }\end{array}$ & .603 & .108 & .677 & .622 \\
\hline & Sig & .000 & .298 & .000 & .000 \\
\hline & $\mathrm{n}$ & 1850 & 1850 & 1850 & 1850 \\
\hline \multirow{3}{*}{ Health } & $\begin{array}{c}\text { Pearson's correlation } \\
\text { coefficient }\end{array}$ & .621 & .677 & .002 & .779 \\
\hline & Sig & .000 & .000 & .985 & .000 \\
\hline & $\mathrm{n}$ & 1850 & 1850 & 1850 & 1850 \\
\hline \multirow{3}{*}{$\begin{array}{l}\text { Total stressful life } \\
\text { situations }\end{array}$} & $\begin{array}{c}\text { Pearson's correlation } \\
\text { coefficient }\end{array}$ & .598 & .622 & .779 & .779 \\
\hline & Sig & .000 & .000 & .000 & .000 \\
\hline & $\mathrm{n}$ & 1850 & 1850 & 1850 & 1850 \\
\hline
\end{tabular}


It is evident from Table (16) that there is a correlation between all domains of life skills with the domains of stressful life situations, where the value of the statistical significance was less than the level of statistical significance (0.05), except for the domain of decision-making skills and problems solving with economic, social and personal stressful life situations, the domain of academic skills with stressful health-related life situations, and the domain of communication skills with others with the domain of family-related stressful life situations, where the statistical significance value was greater than the level of statistical significance $(0.05)$, and for further confirmation, regression test was performed (Table 17).

Table 17. Correlation between total life skills and total stressful life situations

\begin{tabular}{|c|c|c|c|c|c|}
\hline & $\mathrm{R}$ & $\begin{array}{c}\mathrm{R} \\
\text { Square }\end{array}$ & $\mathrm{R}^{2}$ & $\mathrm{Sig}$ & $\mathrm{F}$ \\
\hline $\begin{array}{c}\text { Correlational } \\
\text { relationship }\end{array}$ & .779 & .618 & .614 & $\begin{array}{c}.000 \\
\mathrm{a}\end{array}$ & 152.343 \\
\hline
\end{tabular}

It is evident from Table (17) that the $\mathrm{F}$ test value was equal to (152.343), which is greater than the tabulated value of $F$, and the level of statistical significance reached $\left(.000^{\mathrm{a}}\right)$ which is smaller than the specified value (0.05), and this is enhanced by the value of $\mathrm{R}$ which reached (.779), which explains the strength of the effect between life skills and stressful life situations, in addition to the value of the coefficient of determination $\mathrm{R}^{2}$, which was $\left(.614^{\mathrm{a}}\right)$, and that explains the level of variance in life skills, which is explained by the level of variation in stressful life situations, where it can be said that there is a positive Statistically significant relationship at the level of significance $(\alpha=0.05)$ between life skills and stressful life situations.

The researchers believe that both constitute the foundation of the university personality and follow two paths: one of them starts from the stressful situations that lead to the challenge and the desire to overcome it by acquiring skills, and the second is that the more life skills are acquired, this will reduce the problem resulting from the stressful situations; The university student's possession of life skills provides him/her with the weapon of coexistence, adaptation and success, the ability to achieve effective communication with others, and to transfer what he/she has learned beyond the classroom, and this is one of the highest goals of the desired education in any society that wants for its children a better future life, as the individual cannot live in isolation from others, whether on behalf of his/her family, friends or colleagues, and he/she cannot live without dealing with all concerned parties in society.

Life skills also achieve the goals of education to prepare the citizen for life and face its pressures, as they represent the most important outputs of human learning. Life skills help the individual to manage his/her life, to adapt to $\mathrm{him} / \mathrm{herself}$, to cope with the current changes and to the requirements of life, and to make him/her able to assume social responsibility and solve the problems facing him/her, and to meet the challenges posed by the age in which he/she lives, and achieve his/her self-confidence, and help to act effectively. In different situations, and on social interaction using methods of active communication with others, and positive interaction with life in general, life skills require abilities to perform adaptive, consensual and positive behavior, and these capabilities help the individual to deal effectively and efficiently with the demands of daily life in changing environmental conditions [26].

\section{Recommendations}

- Working on developing the skills of university students and advancing them by encouraging students to develop their cognitive, social and psychological skills within their academic subjects.

- Providing training courses in skills to face stressful life situations among university students.

- Working through some counseling programs to increase the degree of tolerance of stressful life situations among university students.

- The importance of providing a family atmosphere that contributes to the integrated growth of the children's personality, and encouraging them to face stressful life situations and the ability to challenge through methods of social upbringing that make them feel valuable and important.

\section{REFERENCES}

[1] Salman, Asmaa Abdul-Jabbar. (2014). The effect of a proposed program for developing life skills related to the environment and dealing with feelings among kindergarten children. PhD thesis submitted to the College of Education for Girls, University of Baghdad - Kindergarten Department.

[2] Ayyad, Fouad, and Saad Eddin, Hoda, (2010). The effectiveness of a proposed visualization to include some life skills in the technology course for the tenth grade in Palestine, Al-Aqsa University Journal (Human Sciences Series), Volume Fourteen, Issue 1, pp. 174-217.

[3] Saeed, Hebatollah, (2003). Evaluating the Social Studies Curricula for the first year of middle school in light of life skills, an unpublished master's thesis, Ain Shams University in Cairo.

[4] Al-Arini, Abdul Aziz bin Abdullah, (2004). The Student and Life Skills, Journal of the College of Education, Issue 58.

[5] Turk, Rana. (2019). A proposed educational program to develop the life skills of Jordanian university students. Educational Sciences Studies, University of Jordan, 46 (Supplement), 631-650.

[6] Zadeh, M., Awang, H., Islmail, S., \& Shahr, K. (2020). Coping mechanisms of Malaysian adolescents living in 
orphanages through a life skills education program: A multicenter randomized controlled trial. Asian Journal of Psychiatry, 48(1), 1-11.

[7] Hodge, K., Danish, S., \& Martin, J. (2012). Developing a Conceptual Framework for Life Skills Interventions. The Counseling Psychologist, $\mathrm{X}(\mathrm{xx}), 1-28$.

[8] Zins, J. E., Bloodworth, M. R., Weissberg, R. P., \& Walberg, H. J. (2007). The scientific base linking social and emotional learning to school success. Journal of Educational and Psychological Consultation, 17, 191-210. doi:10.1080/10474410701413145

[9] Eskaus, Philip et al. (2005). Development of life skills for secondary education students in the context of future curricula, Cairo: National Center for Educational Research and Development.

[10] Alkriemeen, Raed Ahmed, (2017). Effective Teaching Strategies Between Teaching Competencies and Learning Theories. 1st floor, Amman: Dar Al Academics for Publishing and Distribution.

[11] Saleh, Shafak Muhammad (2019). Life skills for kindergarten children. Proceedings of the nineteenth scientific conference, Journal of the College of Education, Al-Mustansiriya University, 349-370.

[12] Abdel Moati, Ahmed Hussein; And Mustafa, Doaa Muhammad. (2008). Life Skills. 1st floor, Cairo: Dar Al-Sahab.

[13] Yadav, P., \& Iqbal, N. (2009). Impact of life skill training on self-esteem, adjustment and empathy among adolescents. Journal of the Indian Academy of Applied Psychology, $35(10), 61-70$.

[14] Mark 'D. (2000). Health Psychology Theory Research and Practice London. Sage Publications.

[15] Liam, H.,Chau, B., Malhortra, R., Allen, J., Tan, K., \& Chen, H. (2020). Trajectories of antenatal maternal psychological stress and their association with gestational age and neonatal anthropometry: A prospective cohort study of multi-Ethnic Asian women in an urban setting. Asian Journal of Psychiatry, 33(1), 1-5.

[16] Badran, Amro. (2012). Get rid of stress with sports and relax. Cairo: Roses Island Library for Publishing and Distribution.

[17] Camirea, M., Kenellena. K., Rathwell, S., \& Turgeon, S. (2020). Evaluating the Coaching for Life Skills online training program: A randomised controlled trial. Psychology of Sport \& Exercise Journal, 48(1), 2-12.

[18] Patrick, H., Knee, R. C., Canevello, A., \& Lonsbary, C. (2007). The role of need fulfillment in relationship functioning and well-being: A self-determination theory perspective. Journal of Personality \& Social Psychology, 92(4), 434-457

[19] Roth, G., Assor, A., Maymon, Y., \& Kaplan, H. (2006). Assessing the experience of autonomy in new cultures and contexts. Motivation \& Emotion, 30(3), 361-372.
[20] Rudy, D., Sheldon, K., Awong, T., \& Tan, H. (2007), Autonomy, culture, and well- being: The benefits of inclusive autonomy. Journal of Research in Personality, 41(2), 983-1007.

[21] Radwan, A. (2017). the effectiveness of a counseling program based on focusing on developing the life skills of Al-Azhar University students. Journal of educational sciences, 18(4), 21-46.

[22] Sharif, A. Al-Dhalayn, B, \& Suleiman, D. (2016). The effectiveness of a training program for some life skills and its impact on reducing psychological pressures among students of the lower basic stage in Karak Governorate, the Hashemite Kingdom of Jordan. Journal of education, 41, 88-115.

[23] Mekala, C., Aras, R., \& Jayaseelan, M. (2015). Effectiveness of Positive Life Skills Among College Students with Suicide Ideation. Indian Journal of Applied Studies, 5(3), 37-39.

[24] Al-Nuaimi, Latifa and Khazraji, Diaa, (2014). Life Skills for University Students, Diyala Magazine, Issue Sixty-third, pp. 466-502.

[25] Al-Banna, Anwar Hammouda, (2008). Stressful life situations among students of Al-Aqsa University in Gaza Governorate, an exploratory study, Al-Aqsa University Journal, Volume 12, Issue Two, pp. 133-161.

[26] Al-Sayed, Ahmad Jaber, (2001). The use of a program based on the social constructivist learning model and its impact on academic achievement and the development of some life skills for fifth grade pupils, studies in curricula and teaching methods.

[27] Shoukair, Zainab Mahmoud, (2002). Stressful Life Attitudes Scale, 2nd Edition, Cairo, The Anglo-Egyptian Library.

[28] Wafi, Abdul Rahman Jumaa, (2010). Life skills and their relationship to multiple intelligences among secondary school students in the Gaza Strip, an unpublished master's thesis, the Islamic University - Gaza.

[29] Wintre, G., \& Bowers, D. (2007). Predictors of persistence to graduation: Extending a model and data on the transition to university model. Canadian Journal of Behavioral Science, 39(3), 220-234.

[30] Taylor, J. (2006). Life Events and peer substance use and their Relation to substance problems in college students. Journal of Drug Education, 36(2),179 - 191.

[31] Sandler, I.N \& Ramasy, T.B. (1980): "Dimensional analysis of children's stressful life events ", American J. of Community Psychology, (8),285-302.

[32] Saad Eddin, Hoda, (2007). Life skills included in the technology course for the tenth grade and the extent of students' acquisition of it, unpublished master's thesis Islamic University - Gaza.

[33] Hamdi, Nazih (2007). Young people and face pressure. Publications of the Ministry of Culture: Oman 